\title{
An Assessment of Computer Use, Knowledge, and Attitudes of Diabetes Educators
}

\author{
ROBERT M. ANDERSON, EdD; MICHAEL B. DONNELLY, PhD; GEORGE E. HESS, MA \\ University of Michigan Diabetes Research and Training Center \\ Department of Postgraduate Medicine and Health Professions Education \\ Ann Arbor; Michigan
}

A questionnaire to survey attitudes, use, and knowledge of computers was sent to 816 randomly selected members of $A A D E$ to determine the degree to which currently available computer resources are used in diabetes education and to investigate the need for future computing resources designed to support diabetes education. Analysis of the data showed that even diabetes educators who use computers infrequently have a generally favorable attitude toward them. Highest use of computers is in noneducational applications, mostly for word processing and record keeping. Most respondents believe that computers have yet to make a major contribution to the teaching and learning process in diabetes education, and few felt adequately prepared for creative use or development of computer applications. Increasing the role of computers in support of patient education will require encouragement and demonstrations of computer efficacy from health care institutions and professional organizations.
Computer use in health care activities has become widespread in recent years. Computers are being used for a variety of purposes, including prompting physicians, ' education of medical students ${ }^{2}$ and allied health care professionals, ${ }^{3}$ psychiatric assessment and diagnosis, ${ }^{4.5}$ patient interviewing, ${ }^{6}$ and even in operating rooms. ${ }^{7}$ The influx of computers into the health care field is further evidenced by studies assessing the attitudes, knowledge, and behavior of health care providers relative to the use of computers. ${ }^{8-14}$ Several journals such as Computers In Biology and Medicine, Computer Methods and Programs in Biomedicine, Computers in Nursing, MD Computing, and International Joumal of Biomedical Computing are devoted to the use of computers in health care.

Diabetes education and management have participated in this technological revolution as well, as can be seen by the variety of computer software programs that have been developed for use in diabetes care and education. 15.22 Programs are available to help patients adjust insulin doses and plan meals, store data such as glucose values, and provide complete nutritional analysis of dietary components. Computer programs have also been developed for diabetes patient education-to test patients 'knowledge of diabetes, to offer selfpaced instruction, and to provide specialized instruction for adolescents using a variety of formats, including games. In addition, computer programs have been designed to help health care professionals leam about diabetes. To assess the need for additional computer software in diabetes education, the Michigan Diabetes Research and Training Center (MDRTC) surveyed diabetes educators regarding their knowledge, attitudes, and use of computers. The object of this study was to determine the degree to which currently available computer resources are used in diabetes education and to investigate the need for and character of future computing resources designed to support diabetes education.

\section{Methods}

The Measures A questionnaire to survey attitudes, use. and knowledge of computers was developed and mailed to 816 randomly selected members of the American Associa-

This study was supported in part by National Institutes of Health Grant No. 3P60AM20572. National Institute of Diabetes, Digestive and Kidney Diseases, Bethesda, Maryland.

Reprint requests to Robert M. Anderson, EdD, Michigan Diabeles Research and Training Center, Towsley Center for Continuing Medical Education, Room G-1116, Box 0201. Ann Asbor, MI 48109-0201. 
tion of Diabetes Educators (AADE). The nurse and dietitian membership rosters were sampled independently to include 500 nurses and 316 dietitians. Four hundred and four respondents retumed the questionnaire for an overall return rate of $50 \%$. The survey instrument consisted of three parts:

1. The first part of the questionnaire included information about the professional and educational background of respondents and their experience in patient and diabetes education.

2. The second part contained three sections composed of Likert-type attitudinal items rated on a five-point scale varying from Strongly Agree to Strongly Disagree. All respondents were to complete the first section, which assessed general attitudes towards computers. Five of these items expressed positive attitudes toward computers and five expressed negative attitudes. The second and third sections addressed the usefulness of computers in diabetes education. They differed in that the second section was directed to diabetes educators who used computers in some aspect of this work, while the third was for educators who did not use computers in this activity. Sections 2 and 3 contained items of parallel content, differing only in that items in the section for those not using computers were often worded in a conditional rather than a direct form (ie, "computers would be ..." versus "computers are..."). Seven of these items expressed positive attitudes and three expressed negative attitudes.

3. The third part of the questionnaire dealt with experience and skill in the use of computers. One section assessed the frequency of computer use for six specific educational tasks, another assessed the frequency of computer use in five noninstructional activities. A third section assessed self-reported skills in using and developing different types of computer application software.

Thus, in addition to demographic information about respondents, five scales were constructed to assess computer-related attitudes, use, and skills. These scales are referred to as attitudes towards computers, usefulness of computers in diabetes education, use of computers in patient education, other professional use of computers, and computer skills.

Analysis To make useful comparisons, the respondents were divided into three groups. Group 1 was made up of frequent computer users who used computers in some aspect of their work as patient educators (FUPE); group 2 was made up of frequent computer users who did not use computers in their work as patient educators (FUNE); and group 3 was made up of respondents who reported using computers only occasionally or not at all (OCC).

Descriptive statistics and frequency distributions were calculated for the background data. Cronbach's coefficient alphi (a measure of consistency of response) was calculated for each scale as an estimate of reliability. Two-way analyses of yariance with one repeated measure (ANOVA) were calculated for each scale. This analysis provides a simultaneous measure of differences among the three groups (FUPE, FUNE, and OCC) and among items (repeated measure). The purpose of this technique is to answer three questions:

1. Are there differences among the three groups in their responses to the items making up the scales? A significant difference among the groups would be called a group main effect and would be evidenced by differences in the scale means for two or more of the groups.

2. Are there differences among response patterns for individual items within the scales? Differences in the means of individual items making up a scale would be called an item main effect. The Spjøtvoll-Stoline T' post hoc test was used to determine specific pattems in differences among items in a scale. Use of this test made it possible to identify means significantly $(P \leq .05)$ different among sets of mean item scores ranked in a continuum from high to low. This test was carried out on the overall means across groups.

3. Are there differences by both groups and items? Significant differences in item response patterns by group would be called an interaction effect.

To preserve the scale interval labels in an unbiased manner for the attitude item sets, the positive and negative items were analyzed separately.

\section{Results}

The Sample Fifty-seven percent (230) of the respondents were nurses, $40 \%$ (162) were dietitians, and $3 \%$ (12) were other. Sixteen percent of the sample had either a diploma or an associate degree. Forty percent had a bachelor's degree, $40 \%$ had a master's degree, and $1 \%$ had other degrees. Seventy-five percent of the respondents were certified diabetes educators. The mean age of the respondents was 40 years (range, 22 through 66) and they averaged 11 years of experience in patient education, with 8.5 years in diabetes education. The analytical method used required complete data for all items, thus only $348(86 \%)$ of the 404 responses were used in the analysis. Twenty-eight percent (97) of the group reported using a computer frequently, including in their work as patient educators (FUPE). Eighteen percent (63) use a computer frequently but not in their work as patient educators (FUNE). Fifty-four percent (188) use a computer only occasionally or not at all (OCC).

The Scales Reliability estimates for each of the five scales were satisfactory. The values obtained were: attitudes towards computers, 10 items, $\alpha=.81$; usefulness of computers in diabetes education, 10 items, $\alpha=.77$; use of computers in patient education, 6 items, $\alpha=.78$; other professional use of computers, 5 items, $\alpha=.76$; and computer skills, 8 items, $\alpha=.82$. Estimates of this magnitude assure confidence in the reliability of group comparisons made using these scales.

Computer Skills Self-reports of skill in use of different types of computer applications were obtained from respondents. The skill items ranged in difficulty from simple word processing to complex activities such as designing educational software programs. The analysis of this scale identified a significant group main effect $(P \leq .0001)$. The scale means at the bottom of Table 1 indicate that, as might be expected, the FUPE group was most skilled (scale mean $=2.38$ ). The OCC group was least skilled (scale mean $=1.62$ ), although none of the mean ratings indicate a very high level of self-reported competence. The analysis also found significant differences among items $(P \leq .0001)$.

The Spjøtvoll-Stoline T' post hoc test was used to deter- 
Table 1. Mean Responses* to Self-Reports on Items Assessing Skill in Using Computer Applications

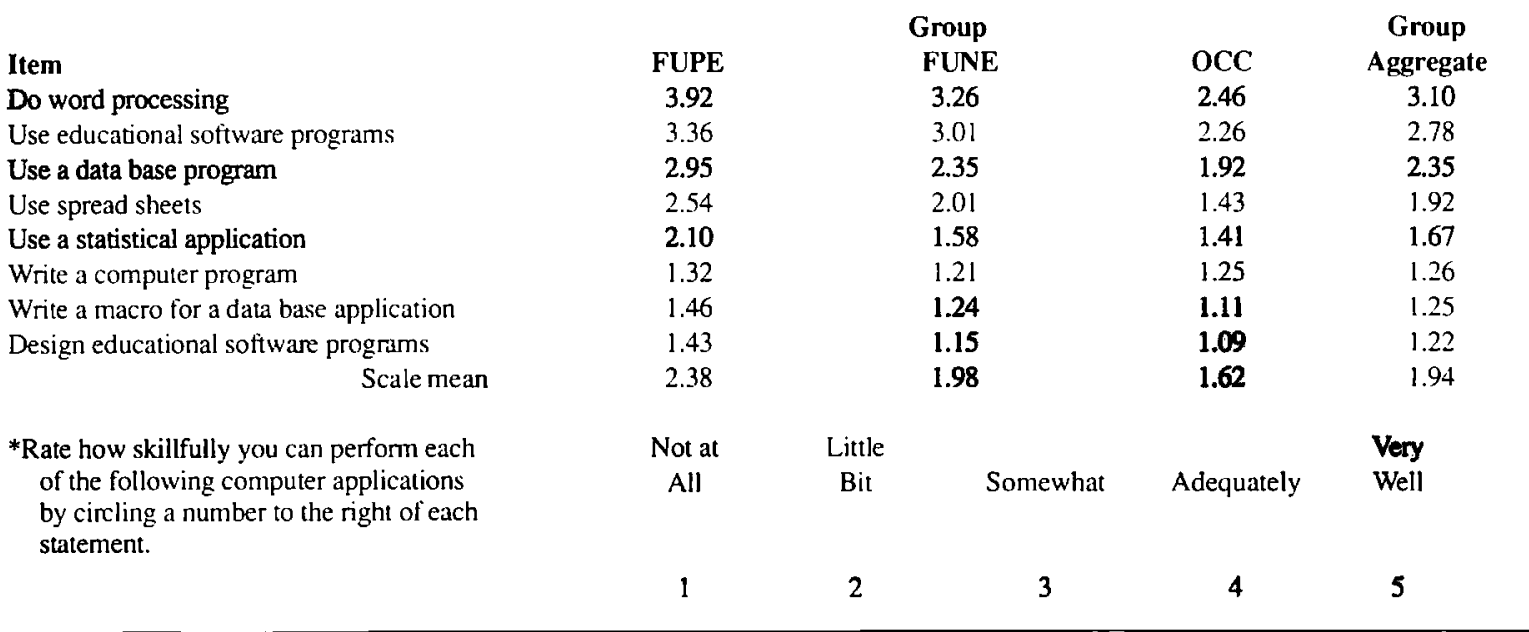

Table 2. Mean Responses* to Items Assessing Positive Beliefs About Computers

\begin{tabular}{|c|c|c|c|c|c|}
\hline \multirow[b]{2}{*}{ Item } & \multicolumn{4}{|c|}{ Group } & Group \\
\hline & FUPE & \multicolumn{2}{|c|}{ FUNE } & $\mathrm{OCC}$ & Aggregate \\
\hline Useful for writing report/papers & 4.76 & \multicolumn{2}{|c|}{4.62} & 4.47 & 4.58 \\
\hline Useful for keeping patient records & 4.58 & \multicolumn{2}{|c|}{4.57} & 4.50 & 4.53 \\
\hline Save time & 4.31 & \multicolumn{2}{|c|}{4.25} & 4.06 & 4.16 \\
\hline Improve efficiency & 4.20 & \multicolumn{2}{|c|}{4.28} & 4.00 & 4.11 \\
\hline Help people leam & 3.97 & \multicolumn{2}{|c|}{4.06} & 3.86 & 3.93 \\
\hline Scale mean & 4.36 & \multicolumn{2}{|c|}{4.36} & 4.18 & 4.26 \\
\hline \multirow[t]{3}{*}{ *In general, I believe that computers: } & Strongly & \multicolumn{3}{|c|}{ Not } & Strongly \\
\hline & Agree & Agree & Sure & Disagree & Disagree \\
\hline & 5 & 4 & 3 & 2 & 1 \\
\hline
\end{tabular}

mine the specific pattem of skill differences in using the various computer applications. On all tables the items are grouped into alternately shaded bands. These indicate that there is a statistically significant $(P \leq .05)$ difference between the overall mean scores of items shaded and items not shaded. Note, this test was carried out on the overall means across groups. Table 1 indicates that the respondents were most familiar with word processing and, to a lesser degree, with educational software programs. There was virtually no familiarity with writing computer programs, writing a macro, or designing educational software. The only mean that was above the scale midpoint (somewhat) was for using word processing applications. The group-by-item interaction was statistically significant. It indicates that the FUPE group means were more spread along the rating continuum than were the means of the OCC group.

Attitudes Towards Computers Separate analyses were done on the positive and negative elements making up this scale. Table 2 presents comparisons of group means for five positive beliefs about computers. The item responses were scaled from 1 (Strongly Disagree) to 5 (Strongly Agree).
Overall the groups expressed positive beliefs about the use of computers (grand mean $=4.26$ ). There was a significant group effect ( $P \leq .001$ ), with the OCC group expressing less positive beliefs than the other two groups. There was also a significant main effect $(P \leq .0001)$ relating to levels of agreement with the various beliefs. The Spjøtvoll-Stoline 'T' post hoc test indicated that the three groups believed that computers were most useful for writing reports and papers and for keeping patient records. Computers were perceived to be less useful in saving time and improving efficiency. Computers were rated lowest in helping people learn.

Agreement with negative beliefs about computers is reported in Table 3. Overall the groups disagreed with these beliefs (grand mean $=2.21$ ). However, the OCC group had a statistically significantly $(P \leq .05)$ higher level of agreement with these negative items than did the other two groups. There were also significant differences $(P \leq .05)$ in agreement with the various negative beliefs. The Spjøtvoll-Stoline T'post hoc test indicated that they disagreed least with the statement that "computers are too expensive." They disagreed most with the statement that computers are "too hard to learn." 
Table 3. Mean Responses* to Items Assessing Negative Beliefs About Computers

\begin{tabular}{|c|c|c|c|c|c|}
\hline \multirow{2}{*}{ Item } & \multicolumn{4}{|c|}{ Group } & \multirow{2}{*}{$\begin{array}{c}\text { Group } \\
\text { Aggregate }\end{array}$} \\
\hline & FUPE & \multicolumn{2}{|c|}{ FUNE } & $\mathrm{OCC}$ & \\
\hline Are too expensive & 2.20 & \multicolumn{2}{|c|}{2.60} & 2.79 & 2.60 \\
\hline Are too impersonal & 1.95 & \multicolumn{2}{|c|}{2.38} & 2.37 & 2.26 \\
\hline Are too complicated & 1.92 & \multicolumn{2}{|c|}{1.97} & 2.31 & 2.14 \\
\hline Cost more than they save & 1.89 & \multicolumn{2}{|c|}{2.03} & 2.24 & 2.10 \\
\hline Are too hard to leam & 1.76 & \multicolumn{2}{|c|}{1.71} & 2.14 & 1.95 \\
\hline Scale mean & 1.94 & \multicolumn{2}{|c|}{2.14} & 2.37 & 2.21 \\
\hline \multirow[t]{3}{*}{ *In general, I believe that computers: } & Strongly & & Not & & Strongly \\
\hline & Agree & Agree & Sure & Disagree & Disagree \\
\hline & 5 & 4 & 3 & 2 & 1 \\
\hline
\end{tabular}

Table 4. Mean Responses* to Items Assessing Positive Beliefs About the Usefulness of Computers

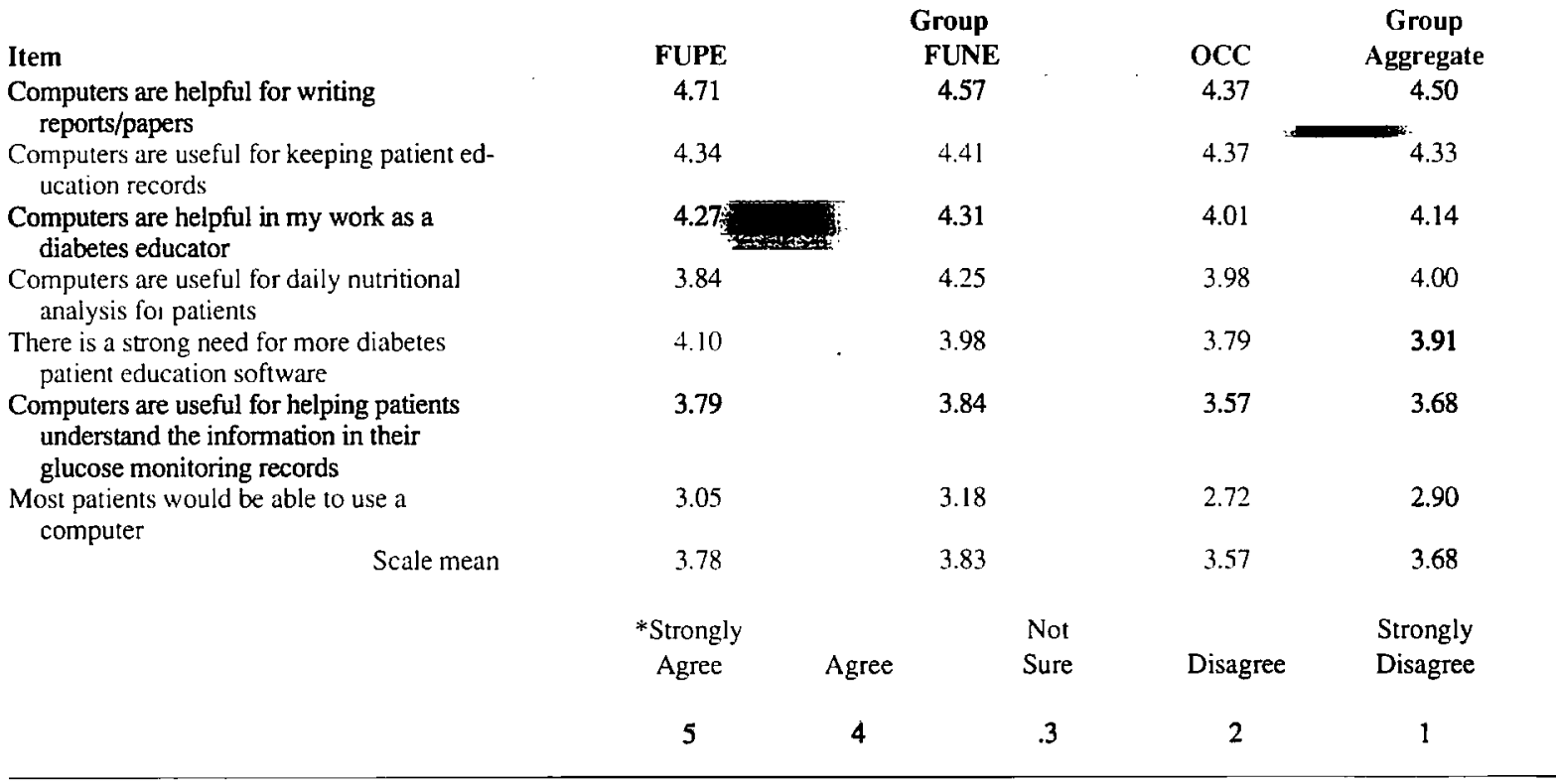

Usefulness of Computers in Diabetes Education The respondents next judged how useful they felt computers to be in a variety of situations in their work as diabetes educators. Table 4 summarizes the results of these analyses. Overall, they agreed that computers were useful; but the mean level of agreement tended to be toward the middle of the scale (grand mean $=3.68$ ). The significant group main effect indicates that there were differences among groups in their assessment of the usefulness of computers. Inspection of the scale means indicates that the OCC group perceived computers to be less useful than did the other two groups. There were also significant differences in perceived usefulness of differing methods of computer use. The Spjøtvoll-Stoline T' post hoc test indicated a very clear differentiation between the various uses of computers. They were perceived to be most useful for writing reports and papers. To a lesser degree, they were perceived to be useful for keeping patient education records. They agreed least with the statement that "most patients would be able to use a computer."

Three items were concerned with negative statements about using computers. Table 5 compares the responses of the three groups on each of these items. There were no group differences for the item "Computers do not enhance my diabetes education program significantly." On average, the groups agreed with this statement. They also tended to agree with the item "In most situations written educational materials are more useful than computers." Again there were no group differences. There were group differences for the item "Most patients would find computers too complicated to use." The OCC group tended to agree with this statement, while the FUPE and FUNE groups tended to disagree with it.

Use of Computers in Patient Education By definition, the FUPE group has reported use of computers in patient 
Table 5. Mean Responses* to Items Assessing Negative Beliefs About the Usefulness of Computers

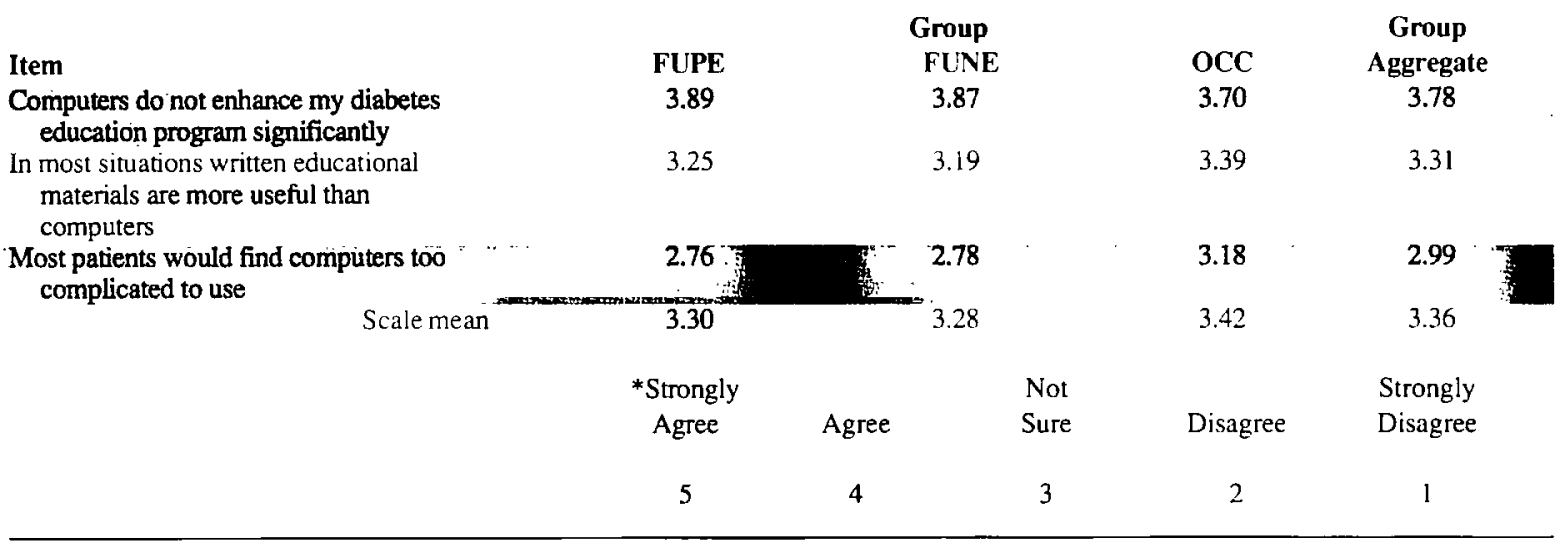

Table 6. Mean Responses* to Items Assessing Computer Use in Patient Education

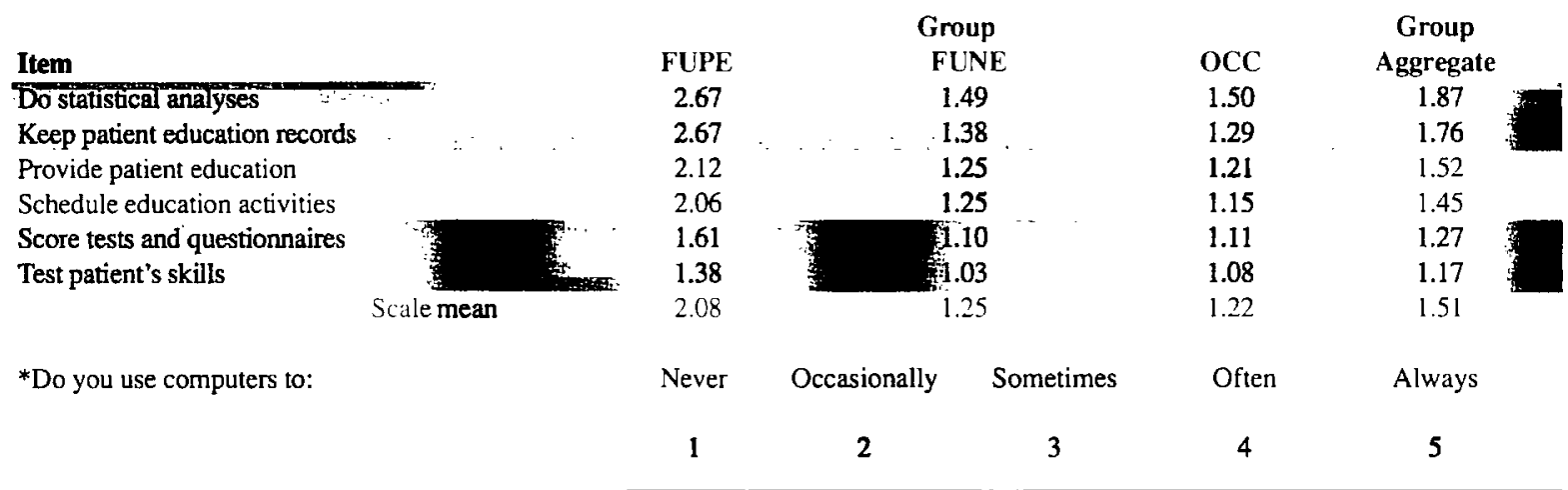

education. Table 6 summarizes how often the respondents reported using computers for a variety of specific patient education activities. On average, they are used infrequently (grand mean $=1.51$, where 1 represents never and 2 represents occasionally). The group mean effect is statistically significant. Inspection of the group means indicates that the FUPE group uses computers more frequently than does the FUNE or OCC groups. The Spjøtvoll-Stoline T'post hoc test indicated that the six items could be grouped into three levels of frequency. Computers are used most often (but infrequently) for statistical analyses and patient education record keeping. They are used less for providing patient education (mean $=1.52$ ) and scheduling education activities (mean $=1.45$ ). They are used least of all for scoring tests and questionnaires (mean $=1.27$ ) and for testing patient's skills $($ mean $=1.17)$.

Other Professional Use of Computers The frequency with which computers are used for a variety of other professional uses is displayed in Table 7 . On the whole, they are occasionally employed in professional work (grand mean = 2.11). As might be expected, the FUPE group used computers most frequently and the OCC group least frequently (Table 7 , the significant group main effect). The significant item main effect indicates that there are differences in the frequency with which computers are used. They are used most frequently for word processing (mean $=3.10$ ) and least frequently for keeping schedules (mean $=1.66$ ) and managing inventories (mean $=1.44$ ).

\section{Conclusions}

The Sample and Measures The diabetes educators who completed this survey were highly educated, with over $80 \%$ having college degrees and the great majority being certified diabetes educators. The respondents were also very experienced patient educators, averaging over 10 years in patient education and more than eight years in diabetes education. The sample was balanced in terms of computer use, with about half the sample reporting frequent computer use, the other half using them only occasionally or not at all. Given the respondents' level of education and experience as diabetes educators, this group was an appropriate one to query regarding computer use in diabetes education.

Although this study was not primarily measurement research, some attention was paid to the psychometric properties of the measures employed in the survey. The fairly high reliabilities of these scales and the high correspondence found with expected differences among the three groups in 
Table 7. Mean Responses* to Items Assessing Noneducational Professional Use of Computers

\begin{tabular}{|c|c|c|c|c|c|c|}
\hline \multirow[b]{2}{*}{ Item } & & \multicolumn{4}{|c|}{ Group } & Group \\
\hline & & FUPE & \multicolumn{2}{|c|}{ FUNE } & $\mathrm{OCC}$ & Aggregate \\
\hline Word processing & & 4.31 & \multicolumn{2}{|c|}{3.09} & 2.25 & 3.10 \\
\hline Record keeping & & 3.23 & \multicolumn{2}{|c|}{2.33} & 1.72 & 2.34 \\
\hline Keeping financial records & & 2.61 & \multicolumn{2}{|c|}{2.12} & 1.53 & 2.00 \\
\hline Keeping schedules & & 2.27 & \multicolumn{2}{|c|}{1.56} & 1.31 & 1.66 \\
\hline Managing inventories & & 1.86 & \multicolumn{2}{|c|}{1.38} & 1.19 & 1.44 \\
\hline & Scale mean & 2.84 & \multicolumn{2}{|c|}{2.09} & 1.60 & 2.11 \\
\hline \multirow[t]{2}{*}{ *Do you use computers for: } & & Never & Occasionally & Sometimes & Often & Always \\
\hline & & 1 & 2 & 3 & 4 & 5 \\
\hline
\end{tabular}

attitudes and skills relating to use of computers offer preliminary support for the reliability and construct validity of the measures used in this study.

Computer Skills The differences in skill in computer use found in this study are what one would expect. Educators who used computers frequently were consistently more knowledgeable about their use than those who used them only occasionally or not at all. Also, the variations in skill at different computer applications are unsurprising, with the sample reporting the highest level of knowledge related to word processing and the next highest level related to use of educational software programs. The self-reporting knowledge related to the more technical use of computers such as statistical applications declined significantly, and the lowest level of knowledge had to do with creating software. The respondents are most knowledgeable about the clerical use of computers, which probably reflects the application of computers that is most helpful to them. This finding could also indicate a lack of secretarial support for diabetes educators. It is important to note, however, that none of the groups reported even adequate skills in use of any applications listed.

Attitudes Toward Computers The diabetes educators who completed this survey were remarkably positive in their attitudes toward computers even if they did not use them on a regular basis themselves. This finding may be due in part to selection bias in that the $50 \%$ of educators who responded to the survey probably had more positive attitudes toward computers than the nonrespondents. However, it is still a significant finding that $50 \%$ of the survey sample had such positive attitudes toward the use of computers.

The respondents' attitudes to using computers in patient education are a bit contradictory. There is consistent agreement that computers are useful for the clerical and administrative aspects of diabetes education, ie, writing reports and keeping patient education records. Also, the respondents agree that there is a strong need for more diabetes education software. However, they are least strong in their support for the statement "Patients would be able to use a computer." They also agreed with statements that computers did not enhance their diabetes education programs significantly and that written materials were more useful than computers.
Other than the response to the item regarding the need for more educational software, the responses to the rest of the items would suggest that diabetes educators value computers largely for their administrative and clerical functions rather than for teaching patients.

One conclusion that could be drawn from these data is that lack of appropriate diabetes education software is preventing more widespread use of computers in patient education. However, the educators' responses to the items about patients' ability to use computers and the value of written materials versus computers make us reluctant to accept this conclusion. It is interesting to note those diabetes educators who did not use computers themselves also felt that computers would be too difficult for patients to use. Conversely, educators who did use computers felt that many patients would be able to use them as well. It is probable that the respondents in this case are projecting their own sense of computer efficacy on to their patients. However, it is possible that the two groups of respondents work with different types of patients.

Computer Use The indication that diabetes educators value computers primarily for their administrative and clerical uses rather than for their use as a teaching and leaming device is further supported by the results in Tables 6 and 7 concerning their own use of computers. Table 6 indicates that the highest reported use in patient education is for statistical analysis and for keeping patient education records. However, the mean scores for the highest use and the most frequent users are below the midpoint (occasional use) on the scale. This is in contrast to their use (Table 7) for word processing and record keeping. which is reported high among the two frequent user groups.

Summary Analysis of these data leads one to characterize diabetes educators, even those who use computers infrequently, as having generally favorable attitudes towards them. Further, even those who report frequent use of computers do not view themselves as adequately skilled, even in the most straightforward computer applications. Highest use of computers is in noneducational applications, confined mostly to word processing and record keeping. These data are consistent with a perception by patient educators that there are few computer applications relevant to the field of diabetes education, and even fewer with any degree of broad 
acceptance. The findings of this survey indicate that the respondents believe that computers (both hardware and software) have yet to make a major contribution to the teaching and learning process in diabetes education. Patient educators' failure to view themselves as adequately prepared for creative use or development of computer applications suggests that the present role of computers in support of patient education will not change significantly without encouragement, support, and demonstrations of efficacy by health care institutions and professional organizations. This may change as computers become more ubiquitous in our society, but for the time being this study suggests that the role of computers in patient education will be largely confined to administrative and clerical tasks.

\section{References}

1. Fletcher SW, Physician acceptance of a computerized health maintenance prompling program. Am J Prev Med 1987:3:19-24.

2. Papa FJ, Meyer S. A computer-assisted learning tool designed to improve clinical problem-solving skills. Ann Emerg Med 1989;18:269-73.

3. Whiteside MF, Whiteside JA. Preparing allied health faculty to use and develop computer-assisted instruction. J Allied Health 1987;16: 247-54.

4. French CC, Beaumont JG. The reaction of psychiatric patients to computerized assessment. Br J Clin Psychol 1987:26:267-78.

5. Overby MA. Psyxpert: an expert system prototype for aiding psychiatrists in the diagnosis of psychotic disorders. Comput Biol Med 1987:17:383-93.

6. O'Connor KP. Hallam RS, Hinchcliffe R. Evaluation of a computer interview system for use with neuro-otology patients. Clin Otolarlyngol 1989:14:3-9.

7. Helzer BA. The computer in the OR. An implementation experience. AORN J 1987:45:1395-402.

8. Thomas B. Development of an instrument to assess attitudes towards computing in nursing. Comput Nurs 1988;6:122-27.
9. Anderson CE. Atlitudes and perceived levels of knowledge of nurse anesthesia educators with respect 10 computers. J Am Assoc Nurs Anesthesiol 1988:56:423-30.

10. Kjerulff KH, Salloway JC. Counte MA. The impact of computer systems in a medical environment. Comput Med Imaging Graph 1989:13:137-43.

11. Bongartz C. Computer-oriented patient care. A comparison of nurses' attitudes and perceptions. Comput Nurs 1988:6:204-10.

12. Knapp RG. Miller MC, Levine J. Experience with and attitudes toward computers in medicine of students and clinical faculty members at one school. J Med Educ 1987:62:344-46.

13. Mandell SF. Resistance to computerization. An examination of the relationsipip between resistance and the cognitive style of the clinician. $J$ Med Syst 1987:11:311-18.

14. Minton PH. Willcutt HC. Psychological aspects of computer use. MD Comput 1985:2:64-67.

15. Snith JM, Pike RA, Jakubow'ski B, Pardoe JR. Survey of computer programs for diabetes management and education. Diabetes Educ $1988: 14: 412-15$.

16. Cook GB. The microcomputer: an extension of the diabetes educator. Diabetes Educ 1982;7(4):12-14.

17. Sivitz WI, Davidson PC, Steed D, Bode B, Richardson P. Computerassisted instruction in intense insulin therapy using a mathematical model for clinical simulation with a clinical algorithm and flowsheet. Diabetes Educ 1989;15:77-79.

18. Schlundt DG. Compuierized behavioral assessment of dietary compliance in IDDM patients. Diabetes Educ 1988;14:567-70.

19. Pennebaker G, Campbell RK. Using pharmacy computer systems to monitor patients with diabetes. Diabetes Educ 1988; 14:350-52.

20. Deleeuw ER. Computers in diabetes nutrition education: a perspective. Diabetes Educ 1987:13(suppl):240-44.

21. Pelican S. Evaluating computer nutrition education software for clients. Diabetes Educ 1987;13(suppl):182. 